\title{
Histochemical demonstration of prostaglandin dehydrogenases in the uterine and chorionic epithelia of the pregnant pig
}

\author{
S. Niimura and K. Ishida \\ Department of Animal Husbandry, Faculty of Agriculture, Niigata University, 2 Igarashi, \\ Niigata, Japan
}

\begin{abstract}
Summary. The NAD-dependent 15-hydroxyprostaglandin dehydrogenase (PGDH) was active in the uterine and chorionic epithelia of the pig at 30,60 and 90 days of pregnancy when PGs of the A, E or F series were used as the substrate. The activity of NADP-dependent PGDH in the same epithelia appeared only when PGB-1 or PGB-2 was used as the substrate.
\end{abstract}

\section{Introduction}

Since the biochemical detection of 15-hydroxyprostaglandin dehydrogenase (PGDH) activity in guinea-pig lungs and the isolation of this enzyme from pig lungs (Änggård \& Samuellsson, 1964, 1966), this enzyme has been demonstrated in various other kinds of animal tissues, and its biochemical nature clarified (see Hansen, 1976). The characteristics and activity of PGDH in the human placenta have been studied by several investigators (Jarabak, 1972; Schlegel, Demers, Hildebrandt-Stark, Behrman \& Greep, 1974; Thaler-Dao, Saintot, Baudin, Descomps \& Crastes de Paulet, 1974; Braithwaite \& Jarabak, 1975; Schlegel \& Greep, 1975; Jarabak \& Braithwaite, 1976; Keirse, Hicks \& Turnbull, 1976; Keirse, Hanssens, Hicks \& Turnbull, 1976; Westbrook, Lin \& Jarabak, 1977a, b). Because the human placenta contains a lot of PGDH (Jarabak, 1972; Schlegel et al., 1974), Jarabak (1972) considered that it might be a major site of prostaglandin metabolism during pregnancy. The present study was an investigation of PGDH activities in the placenta of the pig at different stages of pregnancy.

\section{Materials and Methods}

One Large Yorkshire sow, weighing about $170 \mathrm{~kg}$, and two Landrace sows, both weighing about 150 $\mathrm{kg}$, were mated as required. The animals were slaughtered at 30,60 and 90 days after service. The pieces of placenta for histological observations were fixed in $10 \%$ neutral formalin or Bouin's solution, embedded in paraffin wax, sectioned at $7 \mu \mathrm{m}$, and stained with haematoxylin and eosin. Tissue for the demonstration of PGDH was quickly frozen in liquid nitrogen, sectioned at $15 \mu \mathrm{m}$ on a cryostat, and incubated at $37^{\circ} \mathrm{C}$ for $2 \mathrm{~h}$. The composition of the incubation medium was a slight modification of that used for kidney incubations by Nissen \& Andersen $(1968,1969)$ : $0.3 \mathrm{~mm}$ substrate (Ono Pharmaceutical Co.), 0.75 mm cofactor (Sigma Co.), $0.075 \mathrm{~mm}$ nitro-blue tetrazolium (Sigma Co.), and $0 \cdot 1$ $\mathrm{M}$-sodium phosphate buffer, $\mathrm{pH} 8.0$, in a total volume of $10 \mathrm{ml}$. The substrates used were prostaglandin (PG) A-1, A-2, B-1, B-2, E-1, E-2, F-1 $\alpha$ and F-2 $\alpha$, each of which was dissolved in $0.5 \mathrm{ml}$ ethanol solution and added to the incubation medium. The cofactors were NAD and NADP. Substrate-free but ethanol- and cofactor-containing solution was used for the control incubations.

The activity of $\mathrm{NADH}_{2}$ - and $\mathrm{NADPH}_{2}$-dehydrogenases was detected by the method of Barka \& Anderson (1965) and of alcohol dehydrogenase by the method of Nachlas, Walker \& Seligman (1958) to determine the absence of 'nothing dehydrogenase'. The tissues were all incubated at the same time. 
After incubation, the sections were fixed in $10 \%$ formalin solution and mounted on glass slides with glycerine jelly. The intensity of the enzyme activity was judged by the amount of deposited diformazan granules and estimated on a 5-point scale: strong $(++++)$, moderate $(+++)$, weak $(++)$, slight $(+)$ and absent (-).

\section{$P G D H$}

\section{Results}

When NAD was the cofactor, diformazan granules were uniformly deposited in the cytoplasm of the uterine and chorionic epithelia when sections were incubated in medium containing PGs of the A, E or F series (PI. 1, Figs 1, 2 and 3), but were not present in the sections incubated in medium containing PGB-1 or PGB-2, or in sections incubated in a substrate-free medium. The intensities of the enzyme activity during pregnancy are shown in Table 1.

Table 1. The activities of PGDH with different substrates in the uterine and chorionic epithelia of the pig placenta

\begin{tabular}{|c|c|c|c|c|c|c|c|}
\hline \multirow[b]{3}{*}{ Substrate } & \multirow[b]{3}{*}{ Cofactor } & \multicolumn{6}{|c|}{ Days after service } \\
\hline & & \multicolumn{2}{|c|}{30} & \multicolumn{2}{|c|}{60} & \multicolumn{2}{|c|}{90} \\
\hline & & Uterine & Chorionic & Uterine & Chorionic & Uterine & Chorionic \\
\hline PGA-1 & NAD & + & + & ++ & $++t$ & + & $+1+$ \\
\hline PGA-2 & NAD & ++ & + & + & ++ & + & +++ \\
\hline PGB-1 & NAD & - & - & - & - & - & - \\
\hline PGB-2 & NAD & - & - & - & - & - & - \\
\hline PGE-1 & NAD & ++ & + & + & ++ & ++ & +++ \\
\hline PGE-2 & NAD & + & + & ++ & ++ & +++ & ++ \\
\hline PGF-1 $\alpha$ & NAD & ++ & + & $+1+$ & +++ & +++1 & $+1+$ \\
\hline PGF-2 $\alpha$ & NAD & $+t$ & + & ++ & ++ & $+1+$ & $+1+t$ \\
\hline PGA-1 & NADP & - & - & - & - & - & - \\
\hline PGA-2 & NADP & - & - & - & - & - & - \\
\hline PGB-1 & NADP & + & + & + & + & ++ & + \\
\hline PGB-2 & NADP & ++ & + & ++ & + & ++ & +++ \\
\hline PGE-1 & NADP & - & - & - & - & - & - \\
\hline PGE-2 & NADP & - & - & - & - & - & - \\
\hline PGF-1 $\alpha$ & NADP & - & - & - & - & - & - \\
\hline PGF-2 $\alpha$ & NADP & - & - & - & - & - & - \\
\hline
\end{tabular}

+++ , strong; +++ , moderate; ++ , weak; + , slight; - , absent.

When NADP was the cofactor diformazan granules were found only in the sections incubated with PGB-1 or B-2 and were spread uniformly throughout the cytoplasm of cells in the uterine and chorionic epithelia (PI. 1, Fig. 4). There was very little difference in enzyme activity at the 3 stages of pregnancy (Table 1).

\section{Other dehydrogenases}

Moderate to strong activities of $\mathrm{NADH}_{2}$ - and $\mathrm{NADPH}_{2}$-dehydrogenases were seen in the uterine and chorionic epithelial cell cytoplasm (Pl. 1, Figs 5 and 6), but no alcohol dehydrogenase activity was found in either tissue at any period.

\section{Discussion}

Nissen \& Andersen $(1968,1969)$, who were the first to demonstrate histochemically the presence of PGDH in the rat kidney, used PGs of the E series as the substrate and reported that the enzyme was NAD-dependent and that it was specific. Lee \& Levine (1975) advocated that PGDH should be 

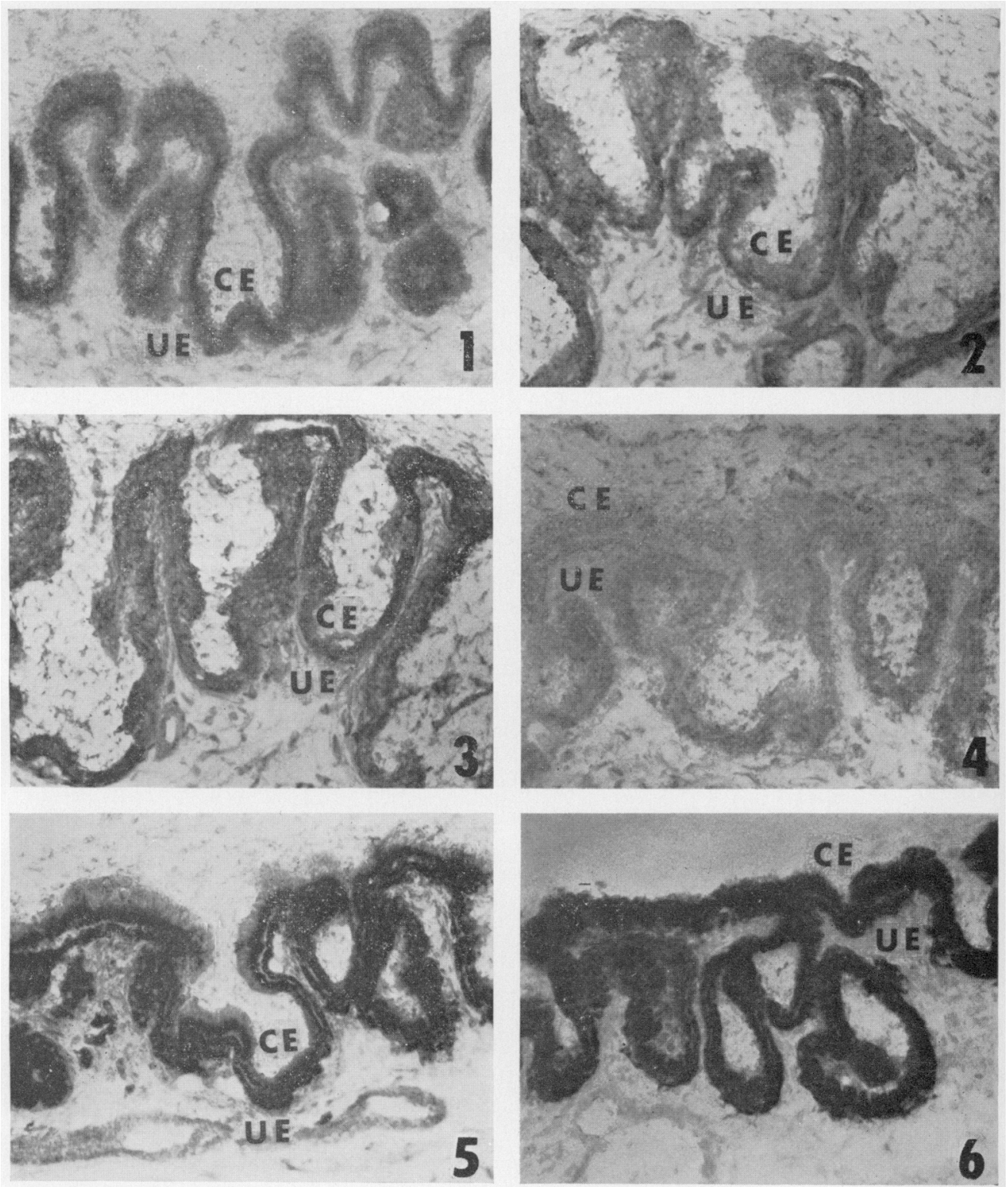

Histochemical demonstration of various dehydrogenases in the uterine (UF) and chorionic (CE) epithelia of the pig placenta. $\times 250$.

Fig. 1. PGDH with PGA-2 as substrate at 30 days of pregnancy.

Fig. 2. $P G D H$ with $P G E-1$ as substrate at 90 days of pregnancy.

Fig. 3. PGDH with PGF- $2 \alpha$ as substrate at 60 days of pregnancy.

Fig. 4. PGDH with PGB-1 as substrate at 90 days of pregnancy.

Fig. 5. $\mathrm{NADH}_{2}$-dehydrogenase at 60 days of pregnancy.

Fig. 6. $\mathrm{NADPH}_{2}$-dehydrogenase at 30 days of pregnancy. 
divided into two types according to their cofactor dependency, i.e. type I (NAD-dependent) and type II (NADP-dependent). The PGDH of type I has been extracted from various kinds of mammalian tissues (Hansen, 1976), while that of type II has been found only in monkey brains, human erythrocytes, pig kidneys (see Hansen, 1976) and human placentae (Westbrook et al., 1977a, b). The human placenta does, however, contain both types of PGDH, the NAD-dependent PGDH oxidizing PGs of the A, E and F series (Jarabak, 1972; Schlegel et al., 1974; Thaler-Dao et al., 1974; Braithwaite et al., 1975; Schlegel \& Greep, 1975; Jarabak \& Braithwaite, 1976) but hardly at all those of the B series (Westbrook et al., 1977a, b) while the NADP-dependent PGDH oxidizes PGA-1 and PGB-1 but not PGEs or PGFs (Westbrook et al., 1977a, b). The present results indicate that the pig placenta also contains two types of PGDH which have a substrate specificity similar to that of the enzymes in the human placenta. The trend to an increased activity of the PG dehydrogenases in later pregnancy needs to be confirmed with more animals and related to the hormonal changes which occur during pregnancy (see Dziuk, 1977).

We thank the Ono Pharmaceutical Company, Osaka, for supplying the prostaglandins.

\section{References}

ÄNGGÅRD, E. \& SAMUELLSSON, B. (1964) Metabolism of prostaglandin $E_{1}$ in guinea pig lung: the structures of two metabolites. J. biol. Chem. 239, 4097-4102.

ÄngGåd, E. \& SAmúlsson, B. (1966) Purification and properties of a 15-hydroxyprostaglandin dehydrogenase from swine lung. Ark. Kemi 25, 293-300.

BARKA, T. \& ANDERSON, P.J. (1965) Histochemistry, Theory, Practice, and Bibliography, pp. 296-333. Harper \& Row, New York.

BraithwaIte, S.S. \& JARABAK, J. (1975) Studies on a 15-hydroxyprostaglandin dehydrogenase from human placenta. Purification and partial characterization. J. biol. Chem. 250, 2315-2318.

DzIUK, P.J. (1977) Reproduction in pigs. In Reproduction in Domestic Animals, 3rd edn, pp. 455-474. Eds H. H. Cole \& P. T. Cupps. Academic Press, New York.

HANSEN, H.S. (1976) 15-Hydroxyprostaglandin dehydrogenase. Prostaglandins 12, 647-679.

JARABAK, J. (1972) Human placental 15-hydroxyprostaglandin dehydrogenase. Proc. natn. Acad. Sci. U.S.A. 69, 533-534.

Jarabak, J. \& Braithwaite, S.S. (1976) Kinetic studies on a 15-hydroxyprostaglandin dehydrogenase from human placenta. Archs Biochem. Biophys. 177, 245254.

Keirse, M.J.N.C., Hicks, B.R. \& Turnbull. A.C. (1976) Prostaglandin dehydrogenase in the placenta before and after the onset of labour. Br.J. Obstet. Gynaec. 83, 152-155.

Keirse, M.J.N.C., Hanssens, M.C.A.J.A., Hicks, B.R. \& TURnbull, A.C. (1976) Prostaglandin metabolism in placenta and chorion before and after the onset of labour. Eur. J. Obstet. Gynaec. Reprod. Biol. 6, 1-6.

LeE, S.-C. \& Levine, L. (1975) Prostaglandin metabolism II. Identification of two 15-hydroxyprostaglandin dehydrogenase types. J. biol. Chem. 250, 548-552.

Nachlas, M.M., Walker, D.G. \& Seligman, A.M. (1958) A histochemical method for the demonstration of diphosphopyridine nucleotide diaphorase. $J$. biophys. biochem. Cytol. 4, 29-38.

Nissen, H.M. \& Andersen, H. (1968) On the localization of a prostaglandin-dehydrogenase activity in the kidney. Histochemie 14, 189-200.

NisSEN, H.M. \& ANDERSEN, H. (1969) On the activity of a prostaglandin-dehydrogenase system in the kidney. Histochemie 17, 241-247.

SCHLegel, W. \& Greep, R.O. (1975) Prostaglandin 15-hydroxydehydrogenase from human placenta. Eur. J. Biochem. 56, 245-252.

Schlegel, W., Demers, L.M., Hildebrandt-Stark, H.E., Behrman, H.R. \& Greep, R.O. (1974) Partial purification of human placental 15 -hydroxyprostaglandin dehydrogenase: kinetic properties. Prostaglandins 5, 417-433.

Thaler-Dao, H., Saintot, M., Baudin, G., Descomps, B. \& Crastes de Paulet, A. (1974) Purification of the human placental 15 hydroxyprostaglandin dehydrogenase: properties of the purified enzyme. FEBS Letters 48, 204-208.

WESTBROOK, C., LIN, Y.-.M \& JARABAK, J. (1977a) NADP-linked 15-hydroxyprostaglandin dehydrogenase from human placenta : partial purification and characterization of the enzyme and identification of an inhibitor in placental tissue. Biochem. Biophys. Res. Commun. 76, 943-949.

Westbrook, C., LiN, Y.-M. \& JARABAK, J. (1977b) NADP-linked prostaglandin B dehydrogenase from human placenta. Fedn Proc. Fedn Am. Socs exp. Biol. 36, 767 .

Received 26 January 1978 